\title{
An information and communications technology (ICT)-enabled method for collecting and collating information about pre-service teachers' pedagogical beliefs regarding the integration of ICT
}

\author{
Michael Vallance* \\ Future University, Fapan
}

\begin{abstract}
This paper describes a method that utilized technology to collect and collate quantitative and qualitative data about pre-service teachers' use of networked technologies during a 12-week undergraduate course, and the impact of this use on their pedagogical beliefs regarding the integration of information and communications technology (ICT). The technologies used captured and analysed students' spoken and written communication while engaging in four synchronous online tasks, and also collected evaluation data from online interviews, surveys and diaries. The richness of data afforded by this ICT-enabled method enabled the research to produce a rich narrative of how the students used the technology and provided evidence of a change in pre-service teachers' pedagogical beliefs during the course.
\end{abstract}

\section{Introduction}

Technology use by teaching practitioners has dramatically altered the learning environment, but data that are gathered to determine its effect is often collected and collated using non-technological methods. This paper demonstrates a method for collecting and collating data in research that involves the use of computer-based technologies by the researcher and the research participants. The pragmatic method is illustrated by the acquisition of data acquired in a Doctoral research study. This information and communications technology (ICT)-enabled method allowed the researcher to capture a variety of qualitative data that, when combined with the

\footnotetext{
*School of Systems Information Science, Department of Media Architecture, Future University, 116-2 Kamedanakano-cho, Hakodate, Hokkaido, T 041-8655, Japan. Email: michael@fun.ac.jp
} 
quantitative data, produced abundant, organized and accessible information that could be efficiently analysed and interpreted.

Before proceeding, it must be clear what this paper is not about. It is not about presenting alterations to the tried and tested research practice of qualitative and quantitative data collection (Trochim, 2005). This proposed ICT-enabled method simply utilizes technology to better serve the researcher by efficiently collecting data and reducing the time spent collating that data. Through better organization, the proposed method allows for a richness in a collection of data that may not be afforded otherwise. It is acknowledged that the researcher must still undertake many of the time-consuming tasks such as transcribing communication and inputting survey responses. However, once completed, this ICT-enabled method facilitates an association between textual and visual communication, which can lead to a richer interpretation by the researcher.

\section{The research study}

To situate the context for exemplifying the data collection and collation, a summary of the research is first provided. The Doctoral research was entitled 'The Impact of Synchronous Inter-networked Teacher Training in ICT Integration', and set out to facilitate new perspectives and experiences in technology-based learning. To enable this, the study investigated the development of pre-service teachers' pedagogical beliefs in the integration of ICT over a 12-week, final-year undergraduate course (Towndrow \& Vallance, 2004) where collaborative synchronous networked tasks were developed and implemented. The contributions by the pre-service teachers to the process of the iterative task development, post-task discussions and the ongoing commentaries on a Bulletin Board System (BBS) provided insights into any change in their pedagogical beliefs.

The relevance of research in synchronous networking for higher education and business organizations was reinforced in May 2005, when Microsoft revealed its vision of the future workspace. In its White Paper entitled 'Digital Workstyle: The New World of Work' (Microsoft, 2005), collaboration was considered a key capability of its future technology and end-users:

Instant messaging, telephony and conference will converge in an environment that gives information workers easy and flexible access to all of their communication tools, with a secure infrastructure that archives the entire collaborative process in one place. Collaborative workspaces will be simple to set up and use with co-workers, partners and customers to create documents, work on projects and find and use relevant business information.

A product such as the shared documents developed during this research may have contained a presence that was facilitated by the collaborative process. In other words, the finished document represented an artefact of a synchronous process of work by a number of collaborators. Thus, this research of the synchronous networking exemplifies a collaborative workspace in practice and provided pre-service teachers with an authentic experience of collaboration that can be transferred to their in-service teaching. 
However, today's technology literate 'Net-geners' (Tapscott, 1997) still require guidance as they develop competencies using synchronous technology, implementing synchronous collaboration, and communicating in a shared space (Levy, 2003). The result of the Doctoral research revealed, for instance, that the participants (the pre-service teachers) developed academic competencies that were more appropriate and desirable for integrating technology than, say, skills-focused technical workshops. A factor in the development of these competencies was task design. In other words, the data revealed that awareness of good task design led to a better understanding of ICT usage to support learning. In addition, the competencies became apparent during the process of collating data. They provided a context for interpretation and discussion of the iterative process of informed ICT integration and associated task design.

Synchronous networked tasks were employed to encourage pre-service teachers to consider their existing practices and facilitate an approach to teaching and learning that supported informed integration of ICT. It is acknowledged that it will be difficult to prove what is good design for synchronous networked learning (Jones \& Asensio, 2000). However, this study was an iterative process and, as suggested by Jones and Asensio, 'the products of design are not outcomes of the design itself but of a deeply social and situated set of work practices' (2000, p. 255). Supporting this, the participants were therefore involved in designing the synchronous tasks, and throughout the 12-week course developed a community that reflected, shared and explained their evolving personal beliefs and understandings of ICT-enabled pedagogical practices. The iterative development and recorded implementation of the tasks, and the ensuing discussions, revealed that the beliefs of the participants emerged and altered through participation in synchronous networked activities. The participants developed a personal understanding of informed ICT integration by sharing and articulating ideas, linking these ideas to their own experiences, engaging with tasks and being exposed to different learning approaches. The qualitative evidence categorized these reflections into three broad competencies: generic, epistemic and declarative. Consolidation, new ideas and core skills were deemed generic competencies and linked to what Goodyear (2001) calls 'transformative potential'. Demonstrating understanding, responding to different points of view and expressing own explanations represented declarative conceptual knowledge and applying such knowledge in problem-solving or arguments. Epistemic fluency, where learners are required to be flexible in their use of knowledge (Morrison \& Collins, 1996), was represented in this study by participants' values and connections to their school environment.

Throughout the research, the participants began to construct and internalize what they were doing, and consider why they were doing certain activities when implementing a synchronous network-based task. This may be considered an initial stage in a process of participants changing their pedagogical beliefs. Subsequent stages of participants' development in pedagogical beliefs were the sharing of their points of view, expressing what they had internalized through discussion and critiquing the shared information. Immersed in these discussions (during the task process, on the 
BBS or during the interviews), the participants refined their understanding of informed ICT integration.

In summary, at the beginning of this study many of the participants viewed their desirable teaching as a transmission of content. As this study developed, the participants were actively involved in, as well as reflecting upon, designing good learning tasks in a synchronous networking environment. The resultant learning shifted from content to activities. To implement synchronous networking tasks successfully, the participants had to become good task designers and focus upon the activities and anticipated cognitive outcomes that may lead to good learning. Goodyear (2001) states that content in these ICT-rich environments becomes the context, and the learning is what the students do with the content. This research revealed that the learning shifted from content to activities; that is, to what students actually did with the tasks' content. This was borne out of a development of academic competencies facilitated by synchronous networked task design and implementation.

\section{Collecting the data: an overview}

The methods used to collect the data needed to enable the research aims to be met. Firstly, to explore quantitative and qualitative data in a natural setting; and secondly, to obtain an understanding of the process of network-based learning (how students used technology) and the product of network-based learning (the impact of use on pedagogical beliefs) within the context of training teachers to integrate ICT (Lortie, 1975; Zhong \& Shen, 2002). This resulted in data being collected from a variety of sources. During the research, the pre-service teachers (hereafter referred to as participants) engaged in four synchronous tasks where each computer action and their corresponding communication (both text and spoken) were digitally recorded. Immediately after each task, a selected participant subgroup was interviewed to reflect upon the collaborative experience, and discuss the activities and associated cognitive outcomes required to complete the synchronous task. At the end of each lesson, all the participants also completed a survey with 14 'yes/no' activity and cognitive outcome questions. The qualitative and quantitative data were consequently analysed and an interpretation offered to the participants and the researcher's colleagues. The interpretation was posted online within one week for all participants to clarify, comment, amend, develop and elaborate prior to the iterative design and implementation of another task two weeks hence. Despite the researcher's 'normal' teaching and administrative load, the immediacy of an interpretation provided a topic for discussion in the following seminars.

The resultant digital method collected data from a variety of sources, and the procedure is represented in Figure 1.

Technology utilization was a focal point of this research but the challenge was how to collect data that would be representative of activities and cognitive outcomes (Knipe \& Lee, 2002) in the process of the synchronous tasks. The researcher needed to collect data of the participants working on a task, the communication that facilitated the task process and completion, and an interpretation by both participants 


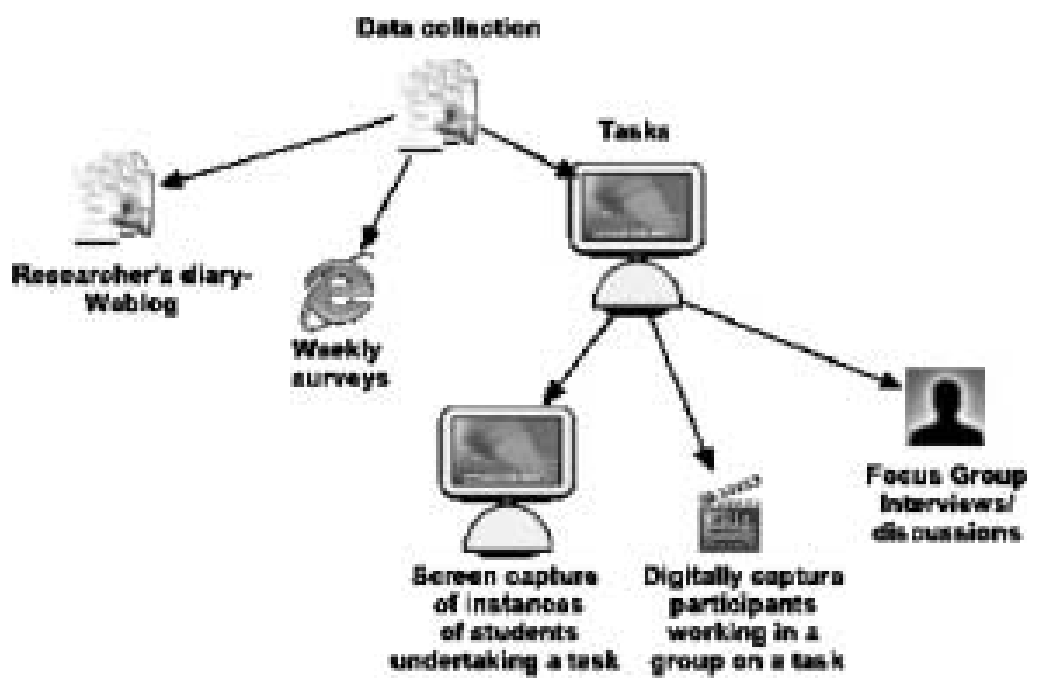

Figure 1. Flowchart for data collection

and researcher of what occurred. The use of digital video would offer greater flexibility (Smith, 1981) and allow for a more detailed retrospective analysis (Edwards \& Westgate, 1987) than using techniques that involved live coding (Bowman, 1994). A video recording would also provide the contexts for meaning of exponents before, during and after participants' actions (Bowman, 1994). Thus, an ICT-enabled procedure for data collection that utilized the existing technologies in the learning environment was developed; in this case, a digital classroom with 30 computers equipped with videoconference cameras, arranged on five hexagonal tables called 'learning islands'.

Two alternative software solutions considered were HyperTranscribe ${ }^{1}$ and Transana. ${ }^{2}$ HyperTranscribe and Transana are designed to synchronize recorded video and a typed transcription. These are useful tools for researchers but were not adopted in this study as the researcher needed to view the data of participants working on a synchronous task and simultaneously capture their computer actions. To the best of the researcher's knowledge, no such software exists-hence the development of this customized ICT-enabled method of data collection and collation.

\section{The tasks}

Having established that the data were collected quantitatively and qualitatively, it is timely to discuss the tasks that were utilized to facilitate this process. The tasks incorporated the use of synchronous networking technologies adhering to Selwyn's framework of activities, integration, collaboration and shared space (Selwyn, 1997). For effective use of ICT, the participants were provided with opportunities to cognitively engage with the materials with 'high levels of learner control' (Steeples et al., 2000, p. 328). Throughout the tasks in this research, the participants were 
provided with a context and an achievable objective, but the design and process of the tasks, and thus associated learning paths, were flexible. In other words, the networked participants determined how each task was implemented. The 12-week undergraduate course that provided the context for this study did not aim to develop technical skills, but focused upon the application of ICT (theory, historical perspectives, pedagogy, practice, procedures, etc.) in order to encourage and develop pre-service teachers' understanding of informed use through an experiential learning process (Towndrow \& Vallance, 2004). All the activities undertaken by the participants were summarized on the class BBS for sharing and asynchronous discussion.

As mentioned, throughout the course there were four instances of data collection while the participants were undertaking a task specifically using synchronous networking technology. The participants' activities were recorded digitally: what they did when using the computer (screen capture) and what they did while working (video and audio capture). Immediately after completing a task, a focus group was formed in order to discuss the task implementation with the researcher. Each task conformed to Selwyn's framework as illustrated in Table 1.

It must be noted at this juncture that tasks 2,3 and 4 were a result of the interpretation of the data and corresponding discussions, and were thus designed in conjunction with the participants. A concern may be the limited number of synchronous tasks; however, within the 12-week undergraduate course a number of additional tasks were undertaken either supporting the synchronous collaboration or more traditional classroom activities. The next section will explain how the different components of the data were collected and collated.

\section{Capturing the tasks}

The task implementation consisted of participants working in groups of three around a computer terminal. Displayed on their monitor screen was a document that was synchronized with other participants at another location. In other words, a number of participants could access one document and type text, and that text would be immediately viewed by participants located elsewhere (synchronous document collaboration). All participants could also simultaneously text chat in the CHAT pane while waiting for the one group to complete their document text. This is illustrated in Figure 2. The software utilized for synchronous document collaboration was iStorm. ${ }^{3}$ The most technology intensive component of the research data included the collection of the participants' communication while on task, and simultaneously recording every computer screen action as they worked on that task.

\section{Capturing students' spoken communication}

The study was conducted in a digital classroom using computers upon which were attached small, digital, Apple iSight cameras. One camera was fitted with a wideangle lens (named Vitacon M-Power) to ensure that all participants' communication 


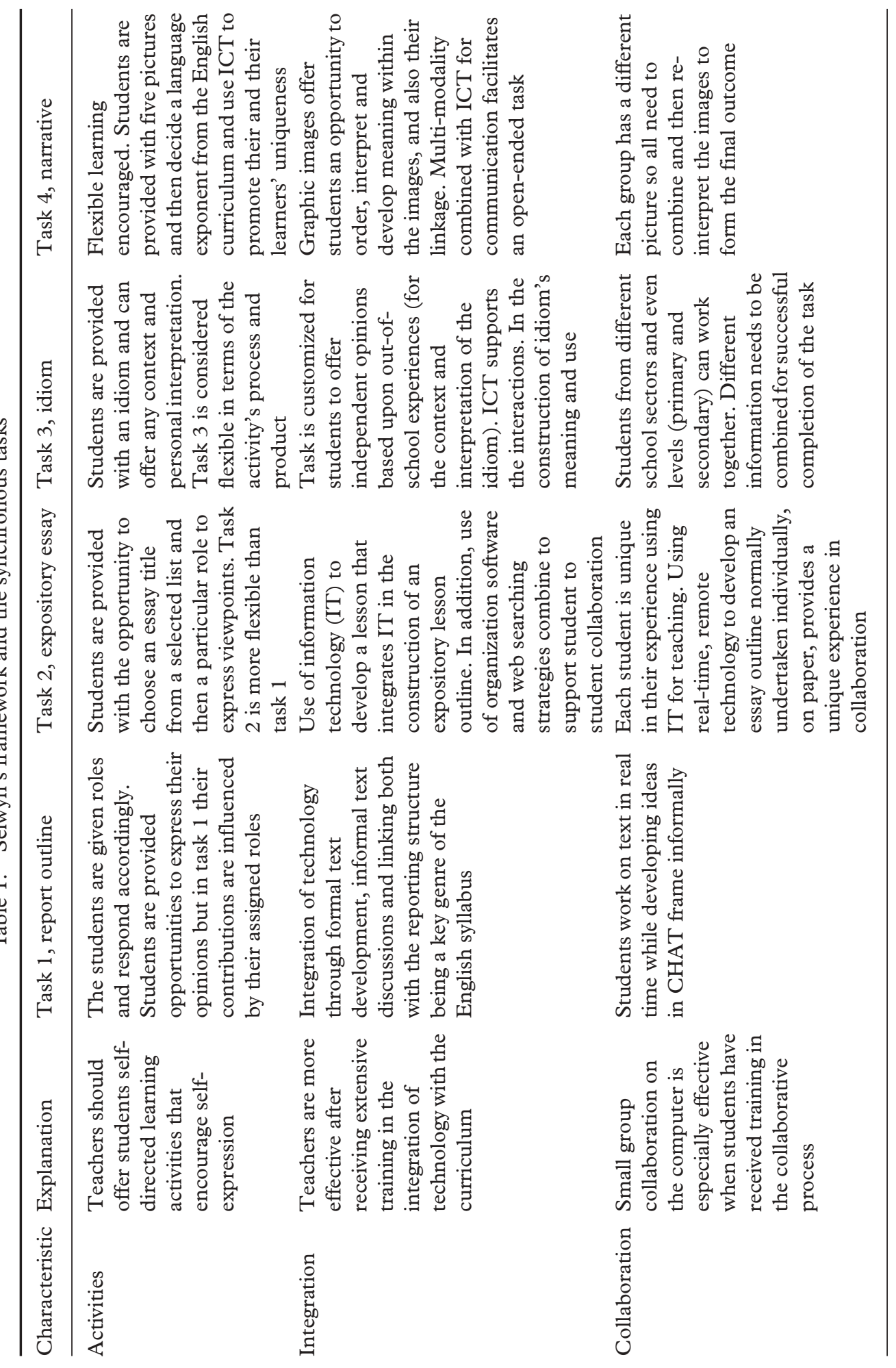




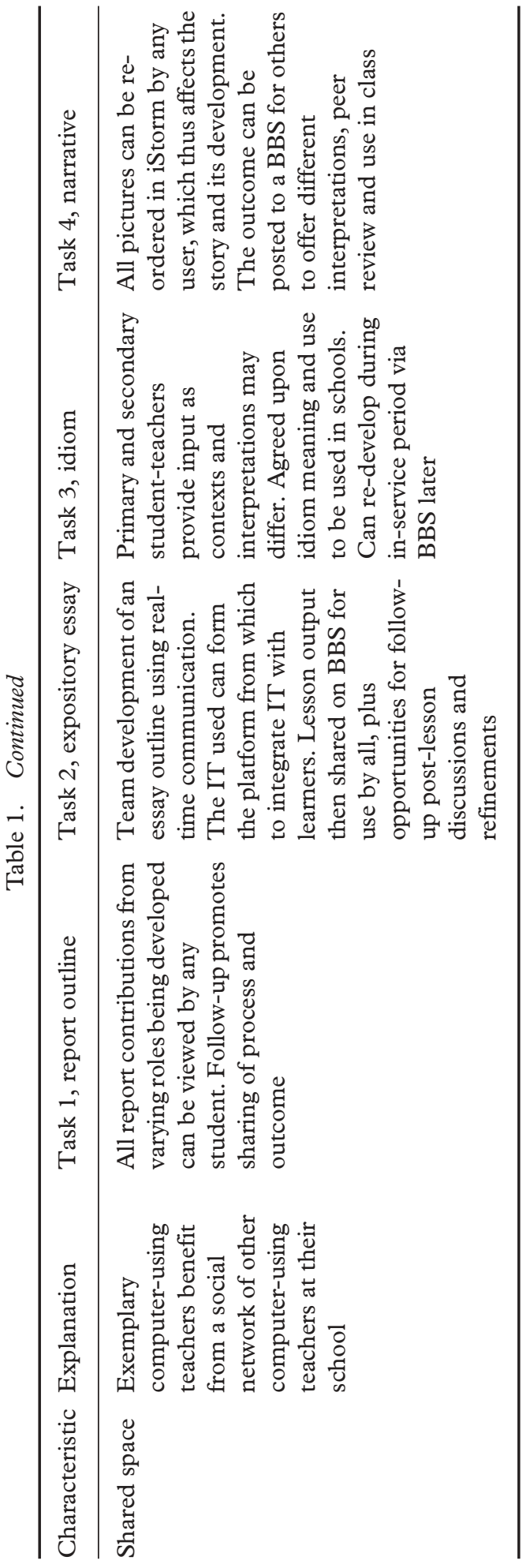




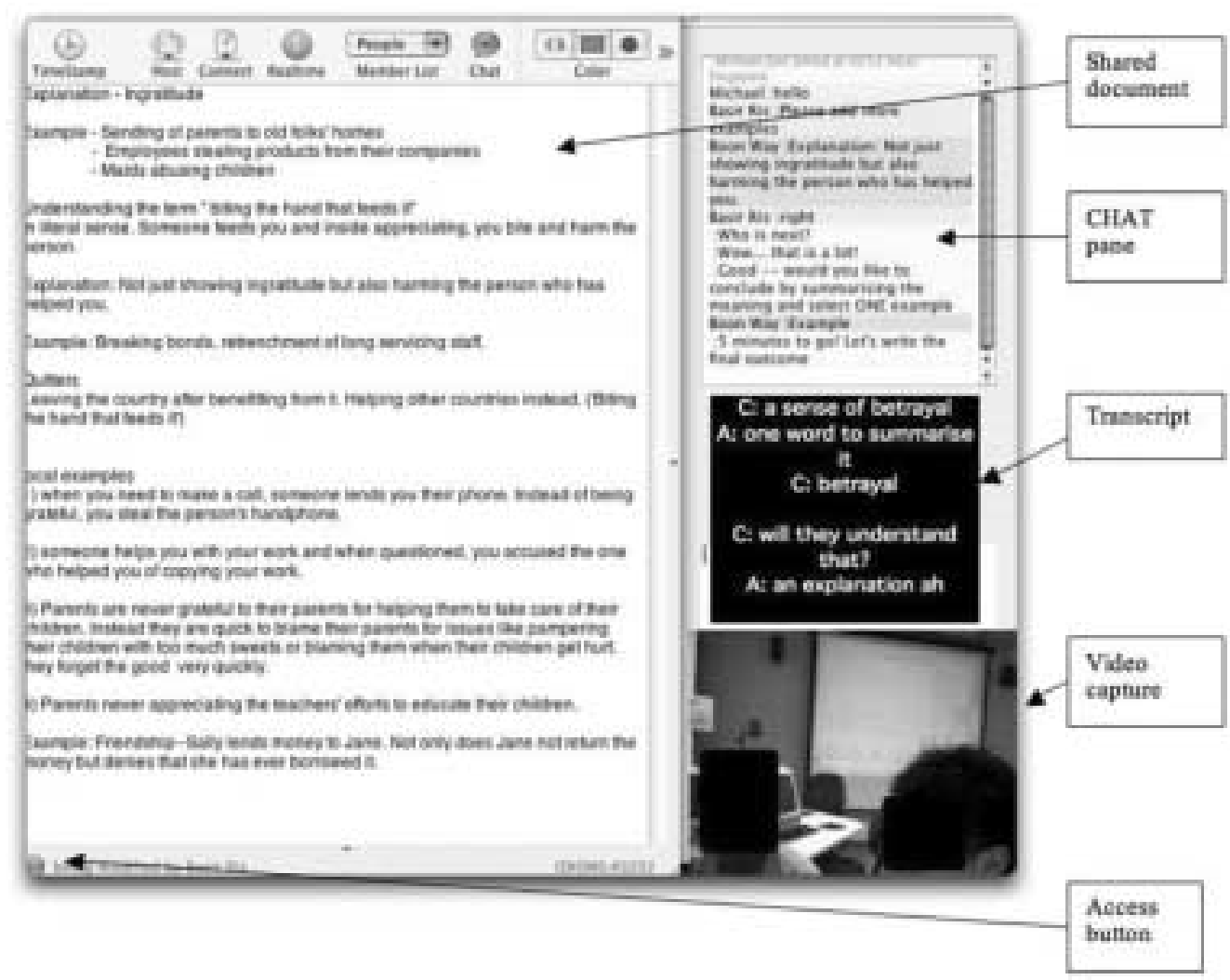

Figure 2. Screen capture actions and communication

while in front of the computer monitor was digitally recorded. The microphone built into the camera was also set to its highest sensitivity and maximum quality.

To record the digital video and audio of the students' communication to the computer hard drive, a free application called QuickTime Broadcaster was utilized. The application was set up to record video at MPEG-4 format, 30 frames per second, with audio set to $16 \mathrm{bit}, 44.1 \mathrm{kHz}$ stereo for a balance between quality and file size. The application's 'Broadcast' button was selected once the participants were assured to be captured within the view of the camera, and then the application was hidden from view by pressing the $\square$ (Command) and H keys. Upon completion of the task, the 'Broadcast' button was again selected to terminate the recording. The resultant spoken communication movie file was thus automatically saved.

\section{Capturing students' computer text communication}

The next challenge was to record all instances of the participants' computer actions. This was more problematic but the digital classroom had been equipped with an application called Apple Remote Desktop. This allowed the teacher's computer to access and view all other computers in the classroom. The participants' actions could therefore 
be viewed from the remote teacher's computer, but how could the actions be digitally recorded? To enable such recording, an application called Snapz Pro $\mathrm{X}^{4}$ was utilized. Snapz Pro $\mathrm{X}$ has the function of recording screen actions as a MPEG-4 video. Therefore, by using the teacher's monitor to display one group's monitor at full screen size, Snapz Pro X was activated to record all screen actions throughout the duration of the task. The most reliable settings for Snapz Pro X were 15 frames per second viewed at $100 \%$. A snapshot of the synchronous document collaboration in action is illustrated in Figure 3. Participants used the primary pane to type their collaborative document and the CHAT pane on the right for more informal text communication.

\section{Collating the communication data}

The next stage of the method was to combine the two sets of data. This was undertaken by first transcribing the spoken communication and identifying exponents representing communicative functions. For example, when observing the digitally recorded movie file and transcript of one group undertaking task 1, a number of functions were in evidence: making decisions, identifying, familiarization, turn-taking, formulating

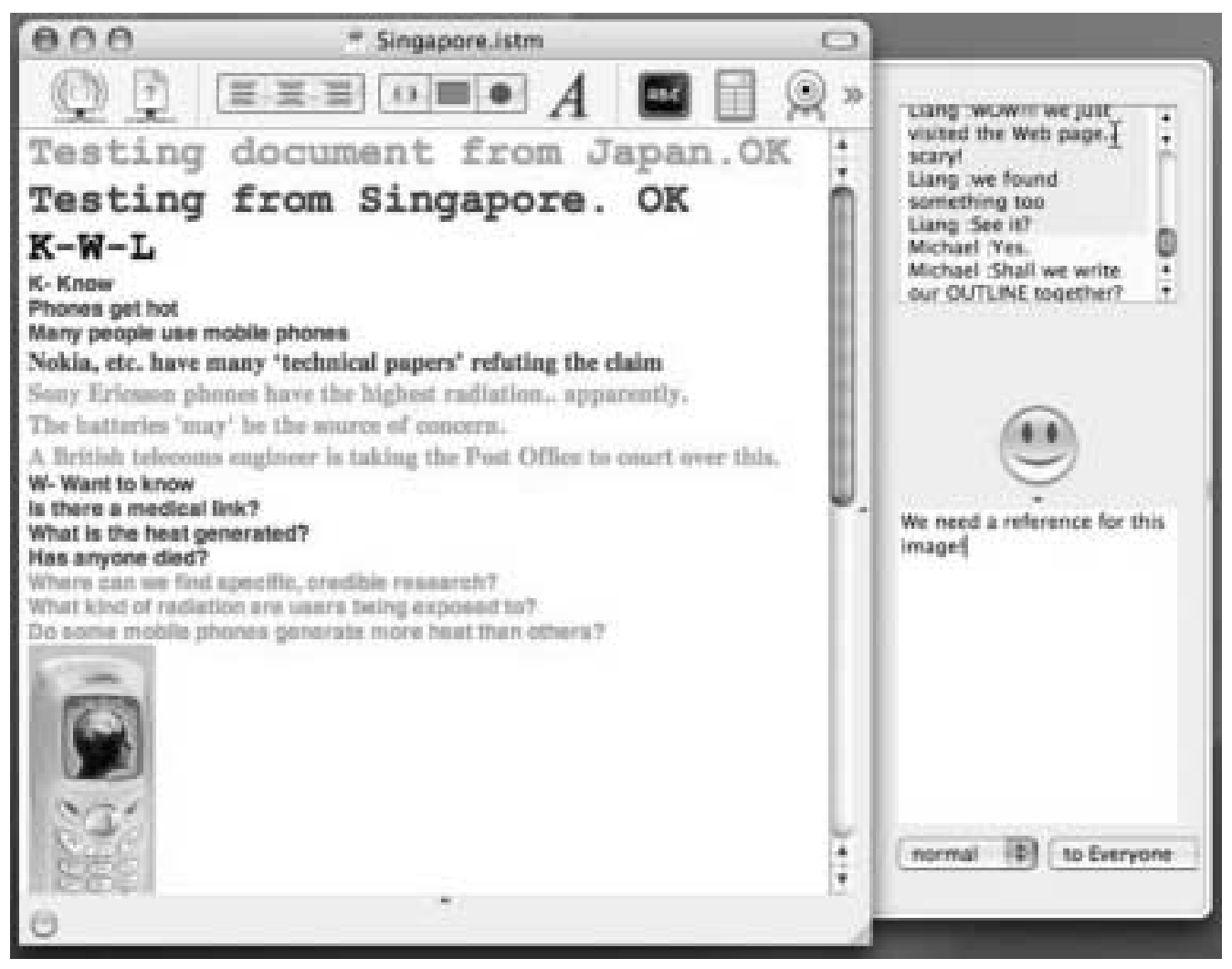

Figure 3. Synchronous collaboration 
answers, associated suggestion and questioning. These functions, and those in tasks 2, 3 and 4, were not pre-determined by the researcher, but resulted through interpretation of the language exponents during the study. This is an important statement as this study had no predetermined expectations of what the participants would discuss nor directed the on-task discourse to focus upon specific functions. The study observed the processes and products that synchronous networking tasks facilitated, and analysed the collated data. Therefore, the functions were derived from an analysis of the data rather than being imposed upon it (Bowman, 1994).

Next, the combined video capture of the spoken communication and the transcribed text was saved as one MPEG-4 movie file. This file was then embedded within the full screen capture of the synchronous document process. Finally, chapter markers were added to the final movie file in order to access each exponent seamlessly during the research analysis.

\section{Combining the spoken communication and its text transcription}

First, each spoken sentence had to be transcribed and then manually tagged with a time stamp. This process was seamless as the spoken communication movie was already in a digital format that could be displayed on the researcher's computer. Next to this movie file was a plain text document, opened in Text Edit, for typing purposes. As the researcher played the movie file, the time stamp was noted and the transcription inserted. Figure 4 illustrates a small portion of transcribed text with time stamps. For example, [00:00:23.00] represented [hour:minute:second:tenths of a second].

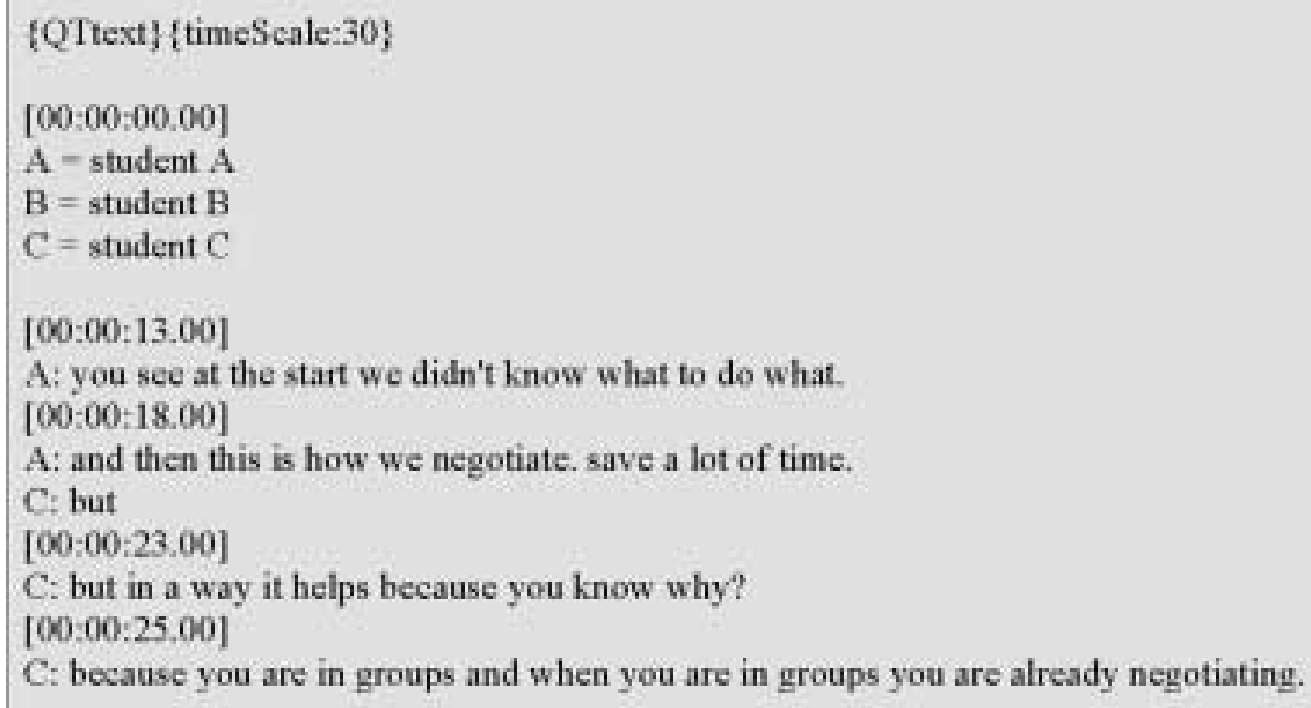




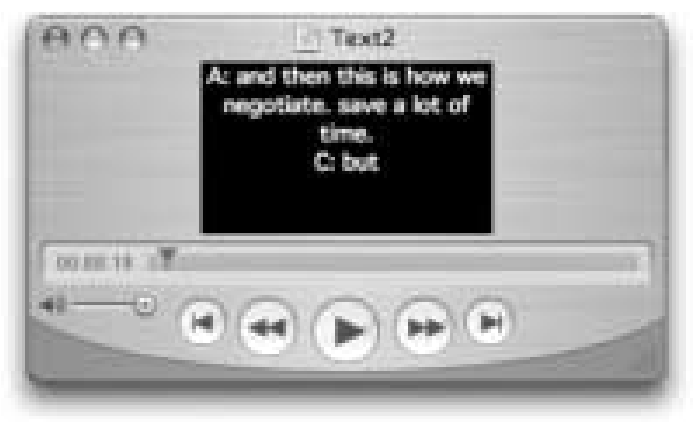

Figure 5. Transcription file in QuickTime

QuickTime Pro was then used to open the transcription file, resulting in it automatically being converted to a movie file with the relevant time stamps (see Figure 5).

The transcription and the previously recorded spoken communication movie files had to be the same duration, to the second, in order to combine synchronously. For files that were slightly different in duration, the end of one of the files had to be cropped. Once the duration of both movie files were synchronized, the transcription file was selected (using Edit-Select All), then added to the spoken communication movie (Edit-Add to Movie). The resultant file consisted of a movie-in-a-movie effect as shown in Figure 6.

The penultimate stage in the procedure was to merge this combined transcription and communication movie file to the screen capture of the recorded participants' actions in the process of generating the collaborative document. The combined transcription and spoken communication movie file was selected (Edit-Select All), then added to the screen capture movie file (Edit-Add to Movie), as shown in

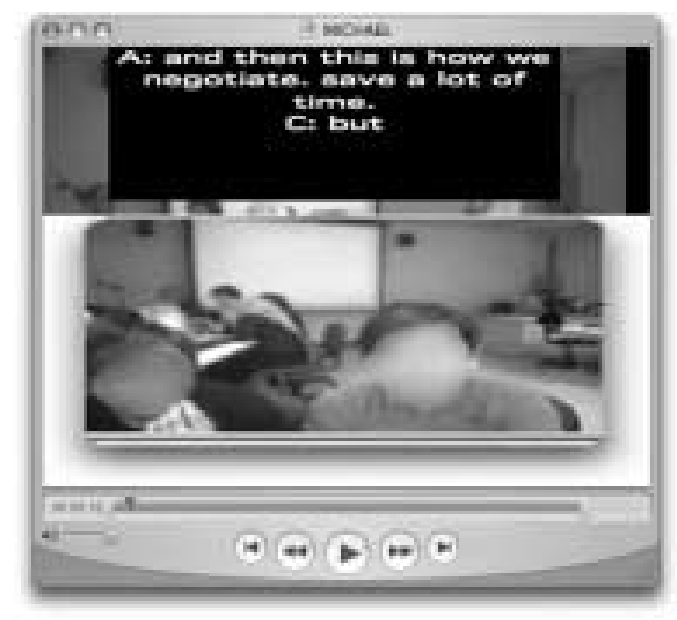

Figure 6. Transcription and communication movie file 
Figure 2. In this case, the transcription was located to one side in order to view paralinguistic features during communication. This was undertaken by opening the QuickTime Show Movie Properties window, selecting Visual Settings and offsetting the text track by adjusting by $320 \times 430$ pixels.

\section{Adding chapter markers}

Finally, chapter markers were added to the collated movie so that the researcher could quickly locate an exponent, listen and view a related example. To simplify and automate this process an AppleScript was made available to the researcher. Entitled ChapterMan (available online at: http://homepage.mac.com/mvallance/FileSharing.html), there are four simple commands;

- Create Chapter Track.

- Add Chapter at Playhead.

- Rename Chapter.

- Delete Chapter.

After opening the collated movie file, a Chapter Track was created using ChapterMan. Then each exponent was identified in the movie and a Chapter added at the desired position. This procedure was repeated until all the exponents were identified. The movie was then saved. This completes the task data collection and collation. As shown in Figure 2, at full screen size the movie file can be accessed to reveal the participants' actions in the document collaboration while simultaneously listening to their spoken communication in the process of the task. This customized approach allowed the researcher to illustrate data in a format considered best for analysing the data.

\section{The interviews}

One group of participants was interviewed immediately after completing each task. Again the interview was digitally captured as it took place in the vicinity of the networked computer. The iSight camera and QuickTime Broadcaster software were used to record the interview. The procedure was similar to that described above where QuickTime Broadcaster was used to record the video and audio to the computer's hard disk. Again the text was transcribed as described above, converted to the MPEG-4 movie format in QuickTime, and added to the interview movie file. Chapter Markers were added again so that the researcher could quickly synchronize examples of related exponents.

\section{The surveys}

At the end of each lesson, all participants completed a survey, which attempted to categorize the activities and cognitive outcomes (Knipe \& Lee, 2002) prevalent in the synchronous document collaboration process. A discussion of the quantitative data is 
outside the scope of this paper but the survey helped focus the interviews on perceived learning facilitated by the process of the collaborative task design and implementation. The data were also utilized by the researcher to seek connections between the captured qualitative data and the quantitative survey data. Essentially, this was an attempt to ensure trustworthiness of the collected data (Guba \& Lincoln, 1981).

\section{The researcher's diary}

The procedure described in the previous section may, at first, appear complicated. However, once the first task had been completed the remaining tasks were collated much more quickly. The most time-consuming, but necessary, procedure was the transcribing. Once that had been completed, the collation was straightforward.

It is believed that the key to the success of this particular study was to display an interpretation of the data as soon as possible after the task completion, using a weblog. The researcher undertook this within one week (despite having a lecturer's teaching load). The interpretation provided content for the discussion in seminars as well as opportunities for participants to express opinions, ask questions, seek clarification and ultimately collaborate in a shared experience of what was meant by informed use of ICT to support learning. Moreover, to facilitate asynchronous communication between the researcher and the participants outside the designated seminars, a class BBS was set up. The postings could be read by all the participants, thereby sharing the information and facilitating a more open discussion of the task actions and the resultant learning (Jonassen et al., 1999; Vallance, 2005).

\section{Conclusion}

Promoters of ICT provide a lot of rhetoric for the need to change education systems, yet none provide concrete proposals that are pedagogically focused (Cuban, 2002) nor do they provide substantive details on how such change can be achieved (Towndrow \& Vallance, 2004). In other words, ICT adoption is gaining recognition as a necessity in education systems worldwide but 'how' and 'why' ICT is adopted and utilized in an informed way remains unclear. One way to provide some clarity and analyse the effect and impact of participants using technology is to consider utilizing the tools readily available in, for example, a digital classroom. This paper has thus provided a context to consider an ICT-enabled method of data collection and collation that may lead to new insights on technology utilization.

\section{Notes}

1. See http://www.researchware.com/ht/

2. See http://www.transana.org

3. See http://www.mathgamehouse.com

4. See http://www.ambrosiasw.com 


\section{References}

Bowman, M. D. (1994) Using video in research, SCRE Spotlight No. 45. Available online at: http:// www.scre.ac.uk/spotlight/spotlight45.html (accessed 25 July 2006).

Cuban, L. (2002) Oversold \& underused. Computers in the classroom (Cambridge, Harvard University Press).

Edwards, A. D. \& Westgate, D. P. G. (1987) Investigating classroom talk (Lewes, Falmer Press).

Goodyear, P. (2001) Psychological foundations for networked learning, in: C. Steeples \& C. Jones (Eds) Networked learning: perspectives and issues (London, Springer Verlag).

Guba, E.G. \& Lincoln, Y.S. (1981). Effective evaluation: improving the usefulness of evaluation results through responsive and naturalistic approaches (San Francisco, CA, Jossey-Bass, Inc.).

Jonassen, D. H., Peck, K. L. \& Wilson, B. G. (1999) Learning with technology: a constructivist perspective (Upper Saddle River, NJ, Prentice-Hall).

Jones, C. \& Asensio, M. (2000) Designs for networked learning in higher education: a phenomenograpic investigation of practitioners' accounts in design, in: C. Steeples \& C. Jones (Eds) Networked learning: perspectives and issues (London, Springer Verlag).

Knipe, D. \& Lee, M. (2002) The quality of teaching and learning via videoconferencing, British fournal of Educational Technology, 33(3), 301-311.

Levy, P. (2003) A methodological framework for practice-based research in networked learning, Instructional Science, 31, 87-109.

Lortie, D. C. (1975) Schoolteacher (Chicago, University of Chicago Press).

Microsoft (2005) Digital workstyle: the new world of work. Available online at: http:// www.microsoft.com/billgates/speeches/2005/05-19ceosummit.asp (accessed 19 July 2005).

Morrison, D. \& Collins, A. (1996) Epistemic fluency and constructivist learning environments, in: B.G. Wilson (Ed.) Constructivist learning environments: case studies in instructional design (Englewood Cliffs, NJ, Educational Technology Publications), 107-119.

Selwyn, N. (1997) Teaching information technology to the computer shy: a theoretical approach to a practical problem, fournal of Vocational Education and Training, 49(3), 395-408.

Smith, H. W. (1981) Strategies of social research (Englewood Cliffs, NJ, Prentice Hall).

Steeples, C., Jones, C. R. \& Goodyear, P. (2000) Beyond e-learning: a future for networked learning, in: C. Steeples \& C. Jones (Eds) Networked learning: perspectives and issues (London, Springer Verlag).

Tapscott, D. (1997) Growing up digital: the rise of the net generation (New York, McGraw-Hill).

Towndrow, P. A. \& Vallance, M. (2004) Using IT in the language classroom: a guide for teachers and students in Asia (3rd edn) (Singapore, Longman).

Trochim, W. M. (2005) The research methods knowledge base (2nd edn). Available online at: http:// www.socialresearchmethods.net/kb/ (acessed 25 July 2006).

Vallance, M. (2005) The challenge of informed use: a unique IT experience for teachers and students from the Peoples' Republic of China, The fournal of Asia TEFL, 2(1), 55-73.

Zhong, Y. X. \& Shen, H. S. (2002). Where is the technology induced pedagogy? Snapshots from a multimedia EFL classroom, British fournal of Educational Technology, 33(1), 39-52. 